\title{
Agostinho da Silva e o conceito de Lusofonia
}

\author{
Renato Epifânio ${ }^{1}$
}

Resumo: Se, por um lado, o pensamento filosófico não pode submeter-se a nenhum desígnio que lhe seja extrínseco, sob pena de se negar, por outro, não pode alhear-se do espaço-tempo onde emerge e se afirma como tal. Tornou-se entretanto uma evidência que Portugal está hoje num processo de viragem estratégica. Depois de, no rescaldo da descolonização, ter apostado tudo na integração europeia, voltando as costas ao espaço lusófono, importa agora que, Portugal, sem voltar as costas à Europa, aposte de novo na convergência lusófona, ou seja, no reforço dos laços com os restantes países e regiões do espaço da lusofonia. A nosso ver, os estudos filosóficos a realizar em Portugal devem ter em conta essa viragem estratégica, promovendo-a na sua área. A Universidade Portuguesa tem, a esse respeito, uma acrescida responsabilidade. Ela deve liderar, no plano reflexivo, essa viragem estratégica. Se não o fizer, a Universidade Portuguesa condenar-se-á à irrelevância. Não há aqui meio termo - ou ela assume a responsabilidade de liderar, no plano reflexivo, essa viragem estratégica em prol da convergência lusófona ou ela falha, por inteiro, a sua missão. Por isso lembramos aqui o pensamento de Agostinho da Silva.

Palavras-Chave: Portugal. Lusofonia. Europa. Agostinho da Silva.

\section{Agostinho da Silva and the concept of Lusophony}

Abstract: If one hand, philosophical thinking can not submit to any plan that is extrinsic to him, under penalty of denying the other, can not distance itself from the space-time emerges and where it is stated as such. Has now become quite evident that Portugal is now in the process of strategic change. Once, in the aftermath of decolonization, have bet everything on European integration, turning his back to the Lusophone space, must now, Portugal, without turning our back on Europe, bet again on Lusophone convergence, ie the strengthening of ties with other countries and regions of the Lusophone space. In our view, the philosophical studies to take place in Portugal should take account of this strategic change, promoting it in your area. A Portuguese University has, in this respect, an increased responsibility. It should lead, in the plane reflective, this strategic change. If you do not, the Portuguese University will condemn ourselves to irrelevance. There is no middle ground here - or she assumes the responsibility to lead, on a reflexive, this strategic shift towards convergence Lusophone or her fault, entirely, to its mission. So here we remember the thought of Agostinho da Silva.

Key-words: Portugal. Lusophony. Europe. Agostinho da Silva.

${ }^{1}$ Professor Universitário. Doutor em filosofia pela Faculdade de Letras da Universidade de Lisboa. Email: novaaguia@gmail.com. 


\section{I - Agostinho da Silva: breve roteiro bio-bibliográfico.}

Nascido no Porto, a 13 de Fevereiro de 1906, vai logo, no ano seguinte, viver para Barca de Alva (Trás-os-Montes), onde passa toda a infância ${ }^{2}$. Ao Porto regressa para realizar o Liceu, findo o qual ingressa, em 1924, na Faculdade de Letras ${ }^{3}$ - primeiro em Filologia Românica, depois, por desentendimentos com Hernâni Cidade, em Filologia Clássica 4 . Durante a Licenciatura, colabora com a Acção Académica, publicação monárquica portuense, e com A Águia, célebre revista da "Renascença Portuguesa", onde, entre outros, se salientaram Teixeira de Pascoaes e Leonardo Coimbra.

Logo após a Licenciatura, concluída em 1928 com a nota de 20 valores, obtém o Doutoramento, igualmente com o "maior Louvor", com uma dissertação intitulada Sentido histórico das civilizações clássicas - sobre esta temática, publica ainda, nos anos imediatamente seguintes, as obras Breve Ensaio sobre Pérsio e $A$ Religião Grega ${ }^{5}$. Entretanto, inicia uma prolongada colaboração com a revista Seara Nova, onde se salientaram, entre outros, António Sérgio, Raul Proença e Jaime Cortesão, com quem, aliás, Agostinho da Silva privou, aquando da sua estadia entre 1931 e 1933, enquanto bolseiro, em Paris (onde frequentou a Sorbonne e o Collège de France), que aí se encontravam enquanto exilados políticos ${ }^{6}$.

\footnotetext{
${ }^{2}$ E aonde ficará para sempre ligado - nas palavras do próprio Agostinho da Silva: "Fiz o curso no Porto, andei por toda a parte quanto é mundo, mas a minha terra continua a ser Barca de Alva." [AGOSTINHO DA SILVA, 1994, p. 16].

${ }^{3}$ Na primeira Faculdade de Letras do Porto, que existiu durante os anos de 1919 e 1931.

${ }^{4}$ Nas palavras do próprio Agostinho da Silva, contudo, a real Licenciatura que ele obteve na Faculdade Letras do Porto foi uma Licenciatura em "Liberdade" - e, posteriormente, um Doutoramento em "Raiva” [cf. AGOSTINHO DA SILVA, 1989, p. 52] -, dado que, ainda nas suas palavras, essa Faculdade era, sobretudo, "uma escola de liberdade" [cf. ibid., p. 147], reflexo da "largueza de espírito de Leonardo Coimbra" [cf. ibid., p. 174] - por isso mesmo, porém, "o governo não gostava dela e fechoua” [cf. ibid., p. 31].

${ }^{5}$ Estas três obras foram recentemente republicadas na colectânea Estudos sobre Cultura Clássica, Lisboa, Âncora, 2002.

${ }^{6}$ Grupo de pessoas às quais, de resto, Agostinho da Silva se manterá ligado, em particular a António Sérgio, a ponto de o ter reconhecido como "mestre" - isto apesar destas suas considerações: “...Sérgio não ousou afrontar os problemas filosóficos mais profundos, as questões de dúvida. Preferia manter-
} 
Regressado a Portugal em 1933, vai para Aveiro onde lecciona no Liceu José Estevão ${ }^{7}$ - por, contudo, se ter recusado a assinar uma declaração de não pertença a sociedades secretas ${ }^{8}$, é demitido do ensino público, tendo então passado a leccionar no ensino particular. Entre 1935 e 1936, volta a sair de Portugal. Desta vez, Madrid foi o destino - aí esteve como bolseiro do Ministério das Relações Exteriores, por convite de Joaquim de Carvalho, cerca de um ano, tempo durante o qual se debruçou, em particular, sobre o misticismo. Em 1937, regressa novamente ao nosso país - nesse mesmo ano, inicia, na Seara Nova, a sua série de Biografias ${ }^{9}$.

Em 1942, publica o opúsculo $O$ Cristianismo ${ }^{10}$, que causou uma grande polémica, tendo-o inclusivamente levado à prisão. Tendo-se tornado insustentável a sua permanência em Portugal, parte, em 1944, para o Brasil - desse ano e do seguinte datam as obras Parábola da Mulher de Loth, Conversação com Diotima e Sete Cartas a um Jovem Filósofo ${ }^{11}$. Aí inicia uma série de actividades - não só, aliás, no Brasil, como ainda no Uruguai e na Argentina. Resultado desse seu activismo foi nada menos do que a criação de quatro Universidades - as Universidades Federais de Paraíba, Santa Catarina, Brasília e Goiás -, bem como de diversos Cursos e Centros de Estudos - nomeadamente, imagine-se, o Centro de Estudos luso-

se na certeza."; "Mesmo como pedagogo, a sua atitude tendia a ser de grande arrogância intelectual." [cf. AGOSTINHO DA SILVA, 1989, p. 55]. Como, contudo, o próprio Agostinho reconheceu, o seu discipulato relativamente a Sérgio cumpriu-se, sobretudo, por oposição: “...mas ele [Sérgio] não me ensinou o racionalismo: ensinou-me antes o irracionalismo, por reaç̧ão minha.” [cf. Francisco Palma Dias, "Agostinho da Silva, Bandeirante do Espírito", in AA.VV., 2000, p. 155].

${ }^{7}$ A experiência enquanto professor do ensino secundário não começou, contudo, aí, já que, em 1929, tinha sido professor no Liceu Alexandre Herculano, em 1930, no Liceu Gil Vicente, em 1931, no Liceu Pedro Nunes, e em 1932, de novo no Liceu Alexandre Herculano.

${ }^{8}$ Nas suas próprias palavras, tão sucintas quanto esclarecedoras: "Pensei bem, e embora não pertencendo a associações secretas e também precisasse de comer, decidi não assinar o papel.” [AGOSTINHO DA SILVA, 1995, p. 35].

${ }^{9}$ A maior parte delas republicadas em Biografias, Lisboa, Âncora, 2003, 3 vols.

${ }^{10}$ Republicado em Textos e Ensaios Filosóficos, Lisboa, Âncora, 1999, vol. I, pp. 67-80.

${ }^{11}$ Igualmente republicadas em Textos e Ensaios Filosóficos, vol. I. 
brasileiros na Universidade de Sófia, em 1959, data de uma das suas mais conhecidas obras: Um Fernando Pessoa ${ }^{12}$.

Naturalizado brasileiro desde $1958^{13}$, torna-se, em 1961, assessor de política cultural externa de Jânio Quadros, o Presidente da República do Brasil na época, colaborando igualmente com a Direcção Geral do Ensino Superior do Ministério da Educação. Nesse mesmo ano, participa ainda na criação de outros Centros de Estudos: nomeadamente, o de Estudos Goianos na Universidade de Goiás, o de Estudos Ibéricos na Universidade de Mato Grosso, o de Estudos Europeus na Universidade do Paraná e o de Estudos Portugueses na Universidade de Brasília, na qual promoveu igualmente o Centro de Estudos Clássicos. Para divulgar entre nós o Centro Brasileiro de Estudos Portugueses da Universidade de Brasília, vem a Portugal, chegando inclusivamente a encontrar-se com Franco Nogueira e Adriano Moreira ${ }^{14}$.

Ainda e sempre de partida, inicia, em 1963, uma digressão pelo Oriente, que o levará, nomeadamente, a Macau, a Timor e ao Japão - neste último país, funda mais um Centro de Estudos. A Portugal regressa, por fim, em 1969, onde virá a assumir diversos cargos: nomeadamente, o de Director do Centro de Estudos LatinoAmericanos do Instituto de Relações Internacionais da Universidade Técnica de Lisboa e o de Consultor do ICALP (Instituto de Cultura e Língua Portuguesa). Em 1987, é condecorado com a Grã Cruz da

\footnotetext{
${ }^{12}$ Republicada em Ensaios sobre Cultura e Literatura Portuguesa e Brasileira, Lisboa, Âncora, 200o, vol. I, pp. 89-117.

${ }^{13}$ Facto por si assumido com a maior naturalidade - daí, a título de exemplo, estas suas palavras: "Porque me naturalizei? Por pensar que a ditadura ia durar para sempre, e como entendi o Brasil e ele a mim, não vi inconveniente na atitude. Para mim, o Brasil traduzia o alargamento tropical das qualidades e dos defeitos dos portugueses.” [AGOSTINHO DA SILVA, 1989, p. 117].

${ }^{14} \mathrm{O}$ segundo, aliás, providenciou, desde logo, o envio de uma biblioteca de cerca de oito mil volumes, tendo vindo igualmente depois a apadrinhar o ingresso de Agostinho da Silva na Academia Internacional de Cultura Portuguesa - como recordou o próprio Agostinho a este respeito: “...Adriano Moreira me levou, sem dizer nada, o colar da Academia Internacional de Cultura Portuguesa, por ele fundada. Foi uma das suas grandes ideias, posta de parte depois da Revolução de 25 de Abril, absurdamente, pois poderia ter um papel muito interessante no mundo, porque era uma associação de gente de todos os países, interessada em cultura portuguesa." [AGOSTINHO DA SILVA, 1994, p. 158].
} 
Ordem de Espada. Em 1988, é publicada a primeira grande colectânea de textos seus (Dispersos, ICALP). Em 1990, protagonizou as Conversas Vadias, programa televisivo que the granjeou uma significativa popularidade. A 3 de Abril de 1994, num Domingo de Páscoa, falece, não sem antes ter dado à luz a obra Ir à Índia sem abandonar Portugal. Prova de que a Verdadeira Viagem se cumpre no interior de nós, de cada um de nós...

\section{II - Pensar Portugal}

O homem não é, ou não é apenas, uma "pura abstracção", mas um ser concreto, universalmente concreto, um ser que, de resto, será tanto mais universal quanto mais assumir essa sua concretude, a concretude da sua própria circunstância. Dessa circunstância faz axialmente parte a "pátria", isso que, segundo José Marinho, configura a nossa "fisionomia espiritual" (MARINHO, 1981, p. 19). Nessa medida, importa pois assumi-la, tanto mais porque, como escreveu igualmente Marinho, foi "para realizar o universal concreto e real [que] surgiram as pátrias" (MARINHO, 2001, p. 502). Ainda nesta esteira, propõe-nos Marinho a distinção entre "universal" e "geral" - nas suas palavras: "O geral tem âmbito mais restrito e insere-se na prossecução de conceitos, o verdadeiro universal está já numa relação da intuição para a ideia e vincula o singular concreto e indefinível com o uno ou o único transcendente." (MARINHO, 1972, p. 45). Daí, enfim, a sua expressa defesa de uma filosofia situadamente portuguesa, não fosse esta "dirigida contra o universalismo abstracto e convencional de escolásticas e enciclopedistas em que têm vivido" (MARINHO, 2007, p. 553).

Os filósofos são, decerto, os grandes pensadores da universalidade. Mas, por isso mesmo, são ou devem ser também os grandes pensadores do "universal concreto", do "universal situado" - e não apenas do "universal geral e abstracto". Se se restringirem apenas a este plano, não serão de resto, verdadeiros pensadores do universal - mas apenas do geral. Só o serão se pensarem, se se 
pensarem, no "universal concreto", no "universal situado". Nessa medida, pensadores portugueses universais serão aqueles que pensarem, se pensarem, no "universal concreto", no "universal situado", ou seja, aqueles que pensarem, se pensarem, na situação concreta da nossa História e Cultura.

Se tivéssemos que escolher o filósofo português que mais profundamente pensou a situação concreta da nossa História e Cultura, escolheríamos, sem desprimor para todos os outros, Agostinho da Silva. Nessa medida, será com ele que aqui iremos dialogar ${ }^{15}$, para pensarmos a nossa situação histórico-cultural, em suma, para pensar Portugal.

\section{III - Entre o Espaço Europeu e o Espaço Lusófono}

A nosso ver, e também na visão de Agostinho da Silva, Portugal só se pode pensar na complementaridade de dois espaços: o espaço europeu e o espaço lusófono. Na complementaridade, não na exclusão mútua, sublinhe-se - ou seja, nem não apenas no espaço europeu nem não apenas no espaço lusófono. Decerto, no espaço europeu, porque Portugal é, desde sempre, um país europeu - o país europeu com as mais antigas fronteiras definidas, mais do que isso, um país que sempre participou activamente na construção da civilização europeia, por extensão, da civilização ocidental, que depois se alargou, sucessivamente, a África, às Américas e mesmo a algumas regiões do Próximo e Extremo-Oriente. Mas não apenas no espaço europeu - ao contrário do que, na ressaca da descolonização, se propôs, dado o amontoado de traumas e ressentimentos que então todos nós, directa ou indirectamente, vivemos. Contudo, como defendemos já no nosso livro A via lusófona: um novo horizonte para Portugal:

${ }^{15}$ Como universo textual, iremos privilegiar as suas entrevistas publicadas em livro, dado que aí Agostinho da Silva muitas vezes foi mais longe, em termos de propostas, do que nos seus ensaios. 
“...depois de mais de três décadas de costas voltadas, por um amontoado de traumas e ressentimentos, todas essas feridas estão agora, finalmente, a cicatrizar, assim abrindo caminho para a recriação do espaço lusófono enquanto um verdadeiro espaço cultural e civilizacional. Sabemos que ainda há quem agite fantasmas do passado, mas o nosso paradigma é um paradigma novo, de futuro.

Queremos que esse espaço lusófono seja o lugar, a casa comum, onde todos os lusófonos tenham, numa base de liberdade e fraternidade, uma vida digna, sem mais adjectivos. Para mais, no caso dos portugueses, se de novo nos viramos para o Atlântico, não é para de novo virar as costas à Europa - somos europeus e por isso manteremos todos os laços: desde logo com a Galiza (...), depois, com os demais povos ibéricos (sem procurar ressuscitar guerras do passado); por fim, com todos os outros povos europeus, em especial os do Sul (com os quais partilhamos uma história milenar). Mas esses laços não são para nós amarras que impeçam o reencontro com a nossa vocação desde logo mediterrânea e atlântica; por fim, por tudo aquilo que nos liga aos demais países lusófonos, universal. Por isso também defendemos o transnacionalismo lusófono - mais do que um sistema, uma dinâmica, através da qual, sem pôr em causa a soberania dos diversos países da CPLP, estes escolham, livremente, cooperar, de modo crescente, nos mais diversos níveis, para benefício de todos (...). Por esse caminho, quem sabe se, mais à frente, não se criará um bloco cultural, social, económico e político - em suma, civilizacional -, que seja um exemplo para outros povos do mundo, num tempo em que o sistema económico e político que nos tem desgovernado se apresenta cada vez mais exangue." (EPIFÂNIO, 2010, p. 116-117) ${ }^{16}$

\section{Daí, também o texto que escrevemos no primeiro número da Nova Águia:}

"Tese, Antítese e Síntese: por um novo paradigma de Portugal"17 Tese - Paradigma do 24 de Abril:

\footnotetext{
${ }^{16}$ Uma continuação desta obra foi entretanto publicada (A Via Lusófona II, Lisboa, Zéfiro, 2015).

${ }^{17}$ Desenvolvemos esta perspectiva num número posterior da revista: "Nos 15 anos da CPLP: a futura pátria de todos nós" [in NOVA ÁGUIA: Revista de Cultura para o século XXI, Lisboa, $\mathrm{n}^{\circ} 7,1^{\circ}$ Semestre de 2011, pp. 27-31].
} 
Tenho da História uma visão hegeliana. Por isso, considero que todos os regimes que caem merecem cair. O Estado Novo não foi excepção. A 24 de Abril de 1974 estava em inteiro colapso. Por isso, caiu. E, com ele, o seu paradigma de Portugal: um Portugal que mantinha um império colonial completamente anacrónico, sem qualquer perspectiva de Futuro.

Antítese - Paradigma do 25 de Abril:

Todas as revoluções são, por natureza, antitéticas. A revolução de 25 de Abril de 1974 também não foi excepção. Por isso, se o Estado Novo defendia um Portugal do Minho até Timor, o paradigma saído da revolução defendeu exactamente o contrário: daí que Portugal tenha virado as costas às suas antigas colónias (com as consequências imediatas que se conhecem e que ainda hoje se fazem sentir), tornando-se apenas em mais um país da Europa.

Síntese - Paradigma do 26 de Abril:

Passado todo este tempo (mais de três décadas), em que os traumas dos ex-colonizadores e dos ex-colonizados já cessaram (senão por inteiro, pelo menos em grande medida), urge um novo paradigma, que faça a devida síntese: recuperando essa visão maior não já de Portugal mas do Espaço Lusófono, em Liberdade e Fraternidade (...)." (AA.VV., 20o8, p. 61).

\section{IV - Agostinho da Silva: prefigurador da Comunidade Lusófona}

Agostinho da Silva é, na nossa perspectiva, o grande teórico desta via, da "via lusófona". Em muitos textos seus, pelo menos desde os anos 50, Agostinho da Silva antecipou, com efeito, a criação de uma verdadeira comunidade lusófona ${ }^{18}$. De tal modo que, mesmo depois de falecer, Agostinho da Silva tem sido recordado por isso. Eis, desde logo, o que aconteceu quando se instituiu a CPLP: Comunidade dos Países de Língua Portuguesa, conforme registámos na nossa obra Perspectivas sobre Agostinho da Silva:

\footnotetext{
${ }^{18}$ Num texto publicado no jornal brasileiro O Estado de São Paulo, com a data de 27 de Outubro de 1957, Agostinho da Silva havia já proposto "uma Confederação dos povos de língua portuguesa”. Num texto posterior, expressamente citado no prólogo da Declaração de Princípios e Objectivos do MIL: Movimento Internacional Lusófono, chegará a falar de um mesmo povo, de um "Povo não realizado que actualmente habita Portugal, a Guiné, Cabo Verde, São Tomé e Príncipe, o Brasil, Angola, Moçambique, Macau, Timor, e vive, como emigrante ou exilado, da Rússia ao Chile, do Canadá à Austrália” ["Proposição" (1974), in AGOSTINHO DA SILVA, 1989, p. 117].
} 
«No dia 17 de Julho desse ano, criar-se-á finalmente a CPLP, a Comunidade de Países de Língua Portuguesa, facto que será noticiado, com destaque, na generalidade dos jornais. Na maior parte deles, realça-se igualmente o contributo de Agostinho da Silva para essa criação, por via do seu pensamento e acção. Eis, nomeadamente, o que acontece na edição desse dia do Diário de Notícias - como se pode ler no texto de abertura da notícia: "A Comunidade dos Países de Língua Portuguesa, hoje instituída em Lisboa, foi premonitoriamente enunciada por Agostinho da Silva em 1956 como 'modelo de vida' assente 'em tudo aquilo que (Portugal) heroicamente fez surgir do nada ou na América ou na África ou na Ásia'.”. Depois, aparece a foto de Agostinho, ladeado pelas fotos de Jaime Gama e José Aparecido de Oliveira, com a seguinte legenda: "Pioneiros da CPLP: Agostinho da Silva (enunciação original), Jaime Gama (primeiro texto diplomático único dos Sete na língua comum) e Aparecido de Oliveira (formalização política da proposta)». (EPIFÂNIO, 2008, p. 108)

Sabemos que este projecto está ainda aquém, muito aquém, do sonho de Agostinho da Silva. A CPLP não é ainda uma verdadeira comunidade lusófona. Mas nem por isso - já vinte anos após a sua criação - a CPLP deixou de ser um projecto em que Portugal deve apostar enquanto desígnio estratégico. De resto, se há inevitabilidades históricas, a criação da CPLP foi, decerto, a nosso ver, uma delas. Se os países se unem, desde logo, por afinidades linguísticas e culturais, nada de mais natural que os Países de Língua Portuguesa se unissem num projecto comum: para defesa da língua, desde logo, e, gradualmente, para cooperarem aos mais diversos níveis. Se estranheza pode haver quanto à criação da CPLP, decorrerá somente do facto de ter nascido tão tarde. Mas isso devese, a nosso ver, a todos os traumas que decorreram da longa guerra e do abrupto processo de descolonização, que tantas feridas causaram, aqui e lá. Já se sabe que as feridas históricas demoram mais tempo a cicatrizar.

Como ainda hoje é reconhecido, Agostinho da Silva foi, de facto, desde os anos cinquenta, o grande prefigurador de uma 
"comunidade luso-afro-brasileira, com o centro de coordenação em África, de maneira que não fosse uma renovação do imperialismo português, nem um começo do imperialismo brasileiro. O foco central poderia ser em Angola, no planalto, deixando Luanda à borda do mar e subir, tal como se fizera no Brasil em que se deixou a terra baixa e se foi estabelecer a nova capital num planalto com mil metros de altitude. Fizessem a mesma coisa em Angola, e essa nova cidade entraria em correspondência com Brasília e com Lisboa para se começar a formar uma comunidade luso-afro-brasileira". (AGOSTINHO DA SILVA, 1994, pp. 156-157)

Na sua perspectiva, assim se cumpriria essa Comunidade Lusófona, a futura "Pátria de todos nós":

"Do rectângulo da Europa passámos para algo totalmente diferente. Agora, Portugal é todo o território de língua portuguesa. Os brasileiros poderão chamar-lhe Brasil e os moçambicanos poderão chamar-lhe Moçambique. É uma Pátria estendida a todos os homens, aquilo que Fernando Pessoa julgou ser a sua Pátria: a língua portuguesa. Agora, é essa a Pátria de todos nós." ${ }^{19}$ (AGOSTINHO DA SILVA, 1998, pp. 30-31)

Daí ainda o ter-se referido ao que "no tempo e no espaço, podemos chamar a área de Cultura Portuguesa, a pátria ecuménica da nossa língua” (AGOSTINHO DA SILVA, 2000, vol. I, p. 139), daí, enfim, o ter falado de uma "placa linguística de povos de língua portuguesa - semelhante às placas que constituem o planeta e que jogam entre si” (AGOSTINHO DA SILVA, 1989, p. 171), base da criação de uma "comunidade" que expressamente antecipou:

"Trata-se, actualmente, de poder começar a fabricar uma comunidade dos países de língua portuguesa, política essa que tem

\footnotetext{
${ }^{19}$ Conforme afirmou ainda: "Fernando Pessoa dizia 'a minha Pátria é a língua portuguesa'. Um dia seremos todos - portugueses, brasileiros, angolanos, moçambicanos, guineenses e todos os mais - a dizer que a nossa Pátria é a língua portuguesa.” [in AGOSTINHO DA SILVA, 1989, p. 122].
} 
uma vertente cultural e uma outra, muito importante, económica" (Ibidem)

Prefigurando até, com esse horizonte em vista, o "sacrifício de Portugal como Nação":

"esse Império, que só poderá surgir quando Portugal, sacrificandose como Nação, apenas for um dos elementos de uma comunidade de língua portuguesa”. (AGOSTINHO DA SILVA, 200o, vol. I, p. 117)

\section{V - Agostinho da Silva: a sua Visão da História de Portugal}

Agostinho da Silva não foi, decerto, um historiador, na acepção mais estrita do termo - nem, de resto, jamais reclamou essa condição. Em muitos dos seus textos, podemos, contudo, encontrar uma original visão da História de Portugal $^{20}$.

Provavelmente, nalguns casos a sua visão será excessivamente mítica - como será o caso da sua visão do "Portugal da Idade Média”:

"o Portugal da Idade Média, o que era? Eu continuo a achar que era uma federação de repúblicas, que a monarquia portuguesa era uma monarquia federal de repúblicas. Quais eram as republicas? Os municípios! Cada um com a sua constituição. Não havia uma constituição para todo o país. Cada concelho tinha a sua constituição chamada foral." (AGOSTINHO DA SILVA, 2001, p. 179)

O mesmo se dirá, talvez, da sua visão do início da expansão ultramarina:

"a ida para Ceuta não é mais do que a continuação da expansão de
Portugal para sul. Os Portugueses tinham empurrado os Mouros,
estes passaram o mar para o lado de lá e nós seguindo-os fomos lá
fazer a nossa sondagem. Evidentemente, que também havia o trigo,
mesmo o bife que se trazia mais barato de Marrocos do que se podia
criar em Portugal, e havia muitas outras coisas, desde o espírito de
aventura até ao facto de o rei estar longe, o que era bom para muita

${ }^{20}$ Conforme desenvolvemos igualmente na nossa obra: Visões de Agostinho da Silva, Lisboa, Zéfiro, 2006. 
gente. Eu acho que o Brasil se desenvolveu daquela maneira entre outras razões porque estava a oito mil quilómetros do rei e, portanto, a coisa podia fazer-se de forma muito diferente daquela que agradaria ao rei." (AGOSTINHO DA SILVA, 2016, p. 13)

Isto apesar de, saliente-se, a sua visão dos chamados "Descobrimentos" não ser nada idílica - Agostinho da Silva chegou a considerar que estes "prejudicaram Portugal":

"Prejudicaram o país, sim, prejudicaram Portugal, porque passou ser fácil enriquecer. Bastava ir e pilhar. Toda a gente que não queria fazer nenhum esforço de trabalho resolveu mudar de vida e lançarse a essa aventura dos Descobrimentos, essa empresa estatal dos Descobrimentos, e isso levou aqueles que ficam em Portugal a viver daquilo que colhíamos lá fora, portanto a não tomar aqui nenhuma espécie de iniciativa." ${ }^{21}$ (AGOSTINHO DA SILVA, 2001, p. 76)

Ainda assim, Agostinho da Silva salvaguardou sempre a singularidade da colonização portuguesa relativamente às demais colonizações europeias - como defendeu a respeito, por exemplo, do Senegal:

\begin{abstract}
"Os Senegaleses, de acordo com a documentação portuguesa da época, sabem hoje como se comportavam os homens que lá ficavam a comerciar e que ali constituíam família africana entrando na mestiçagem. Acham eles que essa gente compreendeu muito bem o Africano, que não os olhava de cima para baixo, que os achava decerto diferentes, mas como muita coisa que constituía uma plataforma em que se podiam entender perfeitamente uns com os outros e entrar em empreendimentos comuns." (AGOSTINHO DA SILVA, 2016, p. 22)
\end{abstract}

De resto, Agostinho da Silva chegou a pôr em causa o termo "colonização", nomeadamente quanto ao Brasil:

\footnotetext{
${ }^{21}$ Daí ainda estas passagens: "Sob o ponto de vista comercial e económico, o Sérgio tem razão, que empresa desastrosa! Portugal só perdeu dinheiro com aquele negócio!” (ibid., p. 133); “o português preferiu a poesia da aventura, do sonho, a ser impelido para as coisas ao trabalhinho que teve o holandês, que teve o inglês... Agora Portugal vai ter problemas." (ibid., pp. 139-140).
} 


\begin{abstract}
"temos de dizer nunca ter sido o Brasil uma colónia senão no sentido grego da palavra. Quando alguém, numa Pátria grega, numa cidade grega, não estava contente com o quanto lá se passava, emigrava tranquilamente para outro lugar com o objectivo de aí viver segundo as suas ideias. Creio ter sido isso que aconteceu no Brasil.

O mesmo sucedeu, no início do século XV, na Costa da Guiné. Os portugueses, descontentes com o rumo tomado por Portugal no século XIV mas, sobretudo, no século XV, emigraram tranquilamente e foram fazer, lá fora, aquele Portugal que não encontravam aqui dentro e que não existe aqui dentro mesmo hoje." (AGOSTINHO DA SILVA, 1998, p. 30)
\end{abstract}

Para tal, invocou o testemunho do Presidente Jânio Quadros, de quem foi assessor, no início dos anos sessenta:

“O presidente Jânio Quadros, numa entrevista que deu, quando lhe perguntaram se ele censurava alguma coisa na colonização portuguesa - esta palavra colonização é perigosa quando se trata do Brasil, eu acho que não houve colonização! -, mas quando lhe perguntaram o que é que ele censurava à colonização portuguesa, Jânio disse: censuro que eles não tivessem subido os Andes, descido do outro lado e tomado conta do Pacífico! Eu estou inteiramente de acordo com o presidente Jânio, a quem assessorei em muita coisa de política africana do Brasil.” (AGOSTINHO DA SILVA, 2001, p. 34)

\title{
VI - Agostinho da Silva: a sua Visão do Futuro de Portugal
}

Apesar de ter chegado a considerar que Portugal havia cumprido a sua "missão histórica" com a descolonização ${ }^{22}$, em muitos outros depoimentos diz-nos, Agostinho da Silva, precisamente o contrário. Simplesmente, doravante, nunca é já

\footnotetext{
${ }^{22}$ Cf.. nomeadamente: "Considero que a missão daquele Portugal que foi, principalmente, um rectângulo situado numa península geograficamente, e apenas geograficamente, pertencente à Europa, foi cumprida e terminou quando acabou aquilo a que se chamou o Império ou as colónias, palavras susceptíveis de muitas interpretações." [AGOSTINHO DA SILVA, 1998, p. 29-30].
} 


\title{
apenas de Portugal que Agostinho da Silva fala, mas de toda a comunidade lusófona:
}

\begin{abstract}
"Quando se diz ter Portugal de fazer alguma coisa, o que tem de ser feito sê-lo-á por todos os homens de língua portuguesa. A missão de Portugal, agora, se de missão poderemos falar, não é a mesma do pequeno Portugal, quando tinha apenas um milhão de habitantes, que se lançou ao Mundo e o descobriu todo, mas a missão de todos quantos falam a língua portuguesa. Todos estes povos têm de cumprir uma missão extremamente importante no Mundo.” (AGOSTINHO DA SILVA, 1998, p. 29-30)
\end{abstract}

E que "missão" é essa? Ouçamos, uma vez mais, o que Agostinho da Silva nos diz:

"Os portugueses levaram a Europa ao Mundo mas, agora, todos aqueles que falam a língua portuguesa, têm o dever de trazer o Mundo à Europa. E espero que tragam esse Mundo tão diferente da Europa, que não deseja aniquilar a Europa como muita gente supõe mas, isso sim, humanizar essa mesma Europa, restituir-lhe aquela força interior e aquela capacidade de imaginação por ela perdida por só imaginar num determinado sentido, por se restringir a um certo campo." (Ibid., pp. 57-58) ${ }^{23}$

Obviamente, esta é uma visão tendencialmente negativa da Europa - facto, que, contudo, Agostinho da Silva nunca escamoteou:

"Realmente, não morro muito de amores por ela. Mas será que a Europa julga que pode governar sem a Península, sobretudo sendo ela, como é, duplamente mediterrânica e atlântica? É bom lembrarmo-nos que foi essa Península que construiu o Bundest Bank e outras coisas de grande dimensão; o Delors vem de vez em quando com um pacote e oferece-nos $10 \%$, esquecendo-se que muito mais que esse dinheiro roubaram-nos eles no Tejo, aquando do negócio da pimenta, e mais tarde também ficaram com o dinheiro que veio do Brasil, a primeira grande exportação do açúcar. Mas depois ainda veio o ouro, e os diamantes, e a madeira

${ }^{23}$ Cf., igualmente, ibid., p. 58: "vamos ser médicos e enfermeiros da Europa ou não seremos nada". 
da Amazónia, foi tudo isso que construiu a Europa. Talvez seja realmente menos pró-europeu, porque entendo que cabe à Península comandar essa união, sem a menor hesitação, e não só deve como pode fazê-lo." (AGOSTINHO DA SILVA, 1995, p. 50)

Daí, também, a sua visão da União Europeia, então CEE: Comunidade Económica Europeia:

"organização inútil, doente, que não se entende, que dificilmente resolve os seus problemas pois levou anos, até, para saber qual deveria ser a cor do passaporte europeu (...). A Comunidade Económica Europeia encontra-se, continuamente, em desacordo consigo própria pois trata-se de pequenas nações provincianas a tentarem agregar-se numa Nação grande.

Nós, que fizemos o Brasil, sabemos o que isso é há muito tempo, há centenas de anos. Além do mais a CEE não é a Europa, como se costuma erradamente dizer, mas apenas o departamento económico da Europa. Qualquer departamento económico deve ser, sempre, secundário porque o que devemos ter é uma Europa cultural onde a economia seja o sustento mas nunca o objectivo." (AGOSTINHO DA SILVA, 1998, p. 6o)

Com efeito, Agostinho da Silva distingue bem as várias acepções de "Europa" - ainda nas suas palavras:

"Há uma Europa, uma Europa geográfica que vem nos livros, que é a que os meninos aprendem na instrução primária. A Europa que vai do Cabo da Roca até aos Urais é uma. Depois há uma segunda Europa, a que deu a cultura europeia para lá dos Urais e para lá do mar, que do lado do mar deu uma cultura europeia que foi sobretudo para a América do Norte, Estados Unidos e Canadá, e que é hoje, num certo sentido, a mais importante, a mais avançada da cultura europeia de descobrimentos de meios de vida, técnicas, por exemplo, muito mais avançadas do que na própria Europa. Mas também foi para outro lado, como para o Japão. Tecnicamente, hoje o Japão é Europa, os Japoneses são europeus durante doze horas por dia, das oito às oito, e depois são Japoneses o resto do tempo. E, além dessa Europa que se estendeu por um lado até à Califórnia e por outro lado até ao Japão, há outra Europa ainda, a que os portugueses e espanhóis foram plantar no mundo. 
Claro que hoje a África é, em grande parte, europeia, europeia até prejudicando muita coisa africana que devia estar viva. E a América Latina? A América Latina é europeia. Além das coisas que nós vemos plantadas, são nitidamente europeias, por exemplo, a África do Sul ou a Austrália ou até determinadas regiões da América Latina, por exemplo, o Chile. O Chile é muito mais europeu que o Brasil, está claro. Ou até a Argentina, já menos europeia do que o Chile, mas europeia também.

De maneira que, quando nós falamos da Europa, estamos a falar daquilo que hoje se chama Europa ocidental ou Ocidente da Europa, que é afinal o hemisfério norte com exclusão, por exemplo, da China, que já é outra coisa, e a tal Europa que se expandiu pelo mundo, que se estendeu pelo mundo. De maneira que, realmente o que hoje se faça na primeira Europa, na Europa aqui do Atlântico aos Urais, vai reflectir-se em todo o mundo. Este parece ser o ponto mais sensível do mundo; o que ali se fizer espalha-se. E, naturalmente, logo a seguir à Europa do lado do Ocidente, os Estados Unidos e o Canadá, a Europa do lado do Oriente, o Japão. Com aquela coisa ainda indistinta e difícil de entender e meio completa que é toda a Rússia asiática, toda aquela Sibéria que naturalmente um dia vai ter a sua vida própria, com populações que não são indo-europeias. Porque também podíamos dizer que a Europa é onde está o indo-europeu e aí temos uma Europa em dificuldades porque o indo-europeu está desaparecendo do mundo, é uma população de muito baixa natalidade, e é possível que um dia desapareça, dissolvida nas outras populações com taxas mais altas de natalidade. Um dos pontos importantes é que ainda podemos definir a Europa como o domínio do indoeuropeu." (AGOSTINHO DA SILVA, 2016, pp. 116-117)

\section{Ora, é precisamente "esta Europa”, como "domínio do indo- europeu”, que se encontra, na visão do Agostinho da Silva, "esgotada":}

"A Europa, com tudo quanto fez, dando tanto instrumento ao Mundo e tendo Portugal transportado grande parte desses instrumentos para toda a Terra, está esgotada. A Europa esgotouse, fisicamente, porque levou toda a sua vida a realizar coisas, a pesquisar para saber, a saber para prever e a prever para poder. Mas as pessoas, a maior parte das pessoas do Mundo - isto 
acontece com oito em dez homens - não são dessa zona europeia ou euro-americana.

Toda essa gente possui outros ideais que não são os do Poder sobre os outros nem os do Poder sobre si próprios. Coibindo-se, restringindo-se a um determinado código que lhe impuseram, a sua ambição não é o Poder mas, fundamentalmente, o Ser.

A Europa esgotou-se no Poder e temos, agora, de partir para outra fórmula que é cada homem ser aquilo que é. Para isso há necessidade de mudar, muitas vezes, as próprias estruturas do Homem e é para isso que estão a avançar as ciências técnicas e médicas. Temos de avançar para modificar, radicalmente, todas as circunstâncias em que até hoje tem vivido o Homem (...). Deu o que tinha a dar e deu muito." (AGOSTINHO DA SILVA, 1998, pp. 55-56)

Face a esse "esgotamento" da Europa, antecipa Agostinho da Silva a emergência de África, do Brasil e da China:

"África vai ser a grande terra do futuro. Hoje, os africanos, depois de terem tido em cima deles, ao longo de mais de 600 anos, gente não africana, os europeus, os muçulmanos, que chegaram primeiro que estes à costa, sentem-se agora finalmente livres. Conseguiram ressuscitar, têm ali gente extraordinária, com qualidades incríveis, muitas das quais se transmitiram ao Brasil. Uma das características do Brasil é realmente estar muito africanizado. O toque de África também foi muito importante, muita gente foi para lá servir. Não os escravos, mas as escravas, as grandes escravas, que passaram os seus costumes, a sua maneira de ser, a muita outra gente no Brasil. De maneira que essa África vai receber duas ajudas extraordinárias: uma é a ajuda do Brasil, que, tanto quanto sei, continua com o Presidente Itamar [Franco]. Hoje, os que querem navegar já não precisam de o fazer por navio, porque hoje navega-se com fax, dá-se a volta ao mundo com fax, e o navio já não é preciso para nada. A outra é a da China, porque lhe vai traçar uma economia para o mundo na junção das duas economias: a de mercado e a outra, a do nosso amigo Li-Peng, quando estiver aperfeiçoada, pronta a funcionar para toda a China e para todo o Oriente, vai passar para a África, muito provavelmente por Moçambique, que é a porta de entrada deles. Então haverá África, haverá Brasil e haverá China, e eu chamo a isso a política do ABC.” (AGOSTINHO DA SILVA, 1995, p. 67) 
E Portugal no meio de tudo isso? - perguntar-se-á. Haverá algum lugar para Portugal? Para Agostinho da Silva, sim - ou pela ligação ao Brasil ou pela ligação à Ibérica - nas suas palavras:

"Duas possibilidades para Portugal: ou o regresso à integridade peninsular ou, pela ligação com o Brasil - e até, por aí, com a África e o Oriente -, salvar-se de ser apenas um sobrevivente como são o Egipto ou a Grécia ou a Pérsia." (AGOSTINHO DA SILVA, 1999, vol. I, p. 167)

Esta, a Ibéria, poderia ser até, na visão de Agostinho da Silva, a grande protagonista da "renovação da Europa":

"Bem, então a Ibéria pode levar à Europa a taxa de natalidade, pode levar para a Europa a racionalização dos produtos, acabar com o inteiro absurdo de a França não poder beber todo o vinho que produz ou não poder comer toda a manteiga que produz também; pode levá-los para o resto do mundo, porque a Ibéria também será não só o condutor à porta da entrada do Terceiro Mundo na Europa, mas será também a saída da Europa para o Terceiro Mundo. Daqui, da Península, poderão sair produtos para África, poderão sair produtos para a América Latina e poderá sair a imaginação que parece estar faltando na Europa: imaginação de ousar navegar através dos mares, para descobrir novas maneiras de manter o mundo." (AGOSTINHO DA SILVA, 2016, p. 67)

"De maneira que essa entrada da Ibéria pode ser uma espécie de renovação da Europa, pode ser uma vacina que a lance para caminhos em que ela própria hesitou e de que ela própria teve medo." (ibid., p. 144)

Paradoxalmente, esta visão agostiniana de Portugal denotava, nas palavras do próprio Agostinho da Silva, um processo de "reaportuguesamento de Portugal", processo que, de resto, considerava imperioso:

"O português vive hoje em Portugal num país que não é Portugal. Num país estrangeiro. Quando toda a gente se riu do plano do Governo que dizia que era preciso reaportuguesar Portugal, o 
problema é que o plano tinha razão. É preciso reaportuguesar Portugal. Engraçado! Ninguém se espanta quando se diz de um país africano que é preciso reafricanizar a África." (AGOSTINHO DA SILVA, 2001, p. 186)

Esse seria, ainda na sua visão, o processo, o projecto, que mais importava cumprir, tanto mais porque, ainda nas suas palavras:

"Há uma ausência de projecto. Portugal está de mãos a abanar por detrás das costas sem saber o que é que há-de fazer, embora precise haver em Portugal um projecto." (Ibid., p. 186)

Daí, enfim, as duas prioridades que definiu:

"Temos de pôr Portugal limpo: na terra, no mar costeiro, naquilo que dá. Esse parece-me ser o primeiro passo. O segundo será voltar ao mar." (AGOSTINHO DA SILVA, 1989, p. 42) ${ }^{24}$

\section{VII - Agostinho da Silva: que Projecto para Portugal?}

Olhando para trás, para a nossa História, considerava Agostinho da Silva que

"Portugal nunca teve um regime político que prestasse a não ser, com todos os defeitos que tinha, até D. Dinis ou parecido" (AGOSTINHO DA SILVA, 2001, p. 228)

Na sua própria vivência, também nunca Agostinho da Silva se reconheceu nos diversos regimes que se sucederam no século XX. Desde logo, no regime republicano - de quem tinha uma visão bastante negativa, como se atesta por este tão longo quanto elucidativo testemunho:

“...nós, os jovens, tínhamos a ideia que de facto a República estava em grande desordem, e continua a ser a ideia de hoje. A ideia de que

\footnotetext{
${ }^{24}$ Ainda quanto à referência ao "mar": "o mar acabou no dia 24 de Abril de 1974, o que é uma atrapalhação para Portugal” [ibidem].
} 
naquela altura Portugal estava em risco de desaparecer do mapa, como nação independente. Na Europa, depois da Grande Guerra, a situação era de cobiça das colónias portuguesas. Evidentemente que elas estavam em risco. O próprio Portugal, pela desordem económica, pela desordem política, por tudo o que acontecia cá dentro - embora muita gente afirmasse que tudo estava bem estava em risco de, provavelmente, se perder.

De maneira que a gente pensa, que a história, de vez em quando, tem os remédios meio brutos para que as coisas se encaminhem até ao ponto que se quer. E o que se levanta perante uma reflexão da história é, por exemplo, o problema de saber se as coisas sucedem apenas porque sucedem, porque houve algo que iniciou a história e depois jogou por aí adiante ou se, na realidade, há qualquer espécie de plano ou de pensamento coordenado que a leva por determinados caminhos e a lança em determinados acontecimentos.

O que é certo é que vem a Ditadura militar, incompetente - eles não tinham jeito para governar o país. O problema principal era por um lado o das finanças, o da economia portuguesa, mas sobretudo o das finanças, e também o problema da ordem pública. Depois surgiu um professor da Universidade de Coimbra, professor de finanças, que já tinha feito alguns comentários sobre a situação em Portugal, que foi chamado para remediar o país e que teve a frieza de alma e de certo modo a coragem de recusar o primeiro convite, porque achou que as condições propostas não eram as que ele queria e só voltou quando lhe deram todas as condições para governar à vontade. $\mathrm{E}$ então dedicou-se a isso, a pôr as finanças em ordem, o que não foi difícil, bastou diminuir ainda mais as possibilidades de vida do povo português para que as contas do Estado ficassem em dia e se pudesse até colocar dinheiro em Londres para render. E por outro lado ele tinha uma noção da ordem pública que não queria saber se tinha de sair de dentro das pessoas para fora ou de fora para dentro. Votou o segundo ponto, uma repressão extremamente dura... Mas a verdade é que vendo a coisa a voo largo, Portugal chegou depois, em 1974, pelas várias espécies ou pelos vários aspectos que a ditadura militar, depois civil, foi tomando, a uma posição, em que encontra, ao sair de tudo isso, um mundo completamente diferente daquele que teria em 1926. Chega ao mundo em que já não há essa cobiça do território de África e em que a própria situação levou a que os territórios africanos se tornassem independentes e, portanto, eliminassem esse risco quanto à situação de Portugal continental. Por outro lado ainda, o que aconteceu foi que sob o aspecto propriamente europeu, a Europa 
é já diferente, com uma Espanha também diferente e em crise, de maneira que não havia nenhum risco imediato para Portugal do lado de fora. Podia haver risco do lado de dentro, mas do lado de fora tinha desaparecido.

Então demarquei-me inteiramente da linha ditatorial. Hoje talvez tivesse percebido melhor. Suponho que hoje percebo melhor e, embora discordando da Ditadura, vejo que ela deu a possibilidade a Portugal de sair da crise em que podia ter naufragado durante a Primeira República e chegar até aos tempos de hoje em que as coisas irão naturalmente de outra maneira." (AGOSTINHO DA SILVA, 2001, pp. 45-46) ${ }^{25}$.

\section{Não obstante esta visão quase “justificativa” do Estado $\mathrm{Novo}^{26}$, a verdade é que este também não foi um regime que tenha dado ouvidos a Agostinho da Silva, desde logo quanto à criação de uma "comunidade de língua portuguesa":}

"a ideia geral talvez fosse, e eu próprio a defendia e procurei no
princípio da guerra em Angola, junto de autoridades portuguesas,
por exemplo de um embaixador no Rio, pôr-lhes essa ideia na

${ }^{25}$ Cf., igualmente, ibid., pp. 164-165: "Eu já tinha reflectido bastante sobre essa ditadura e tinha pensado que Portugal com o regime da Primeira República, de perpétua incerteza, de discussão, conflito, inapetência, incompetência de encontrar um verdadeiro governo e um verdadeiro plano para o país, quando se chegou por essa altura de 1926, parece-me agora, parecia-me já em Brasília, que a situação era muito complicada, que o país estava sem nenhuma credibilidade exterior, sem o respeito de ninguém, tanto dentro como fora, havia o problema das colónias, que todo o mundo ambicionava, de maneira que podia dizer-se que Portugal era um fruto maduro que as potências europeias, inclusive a Espanha, podiam tomar e dominar quando quisessem, bem como a parte africana portuguesa. Então podemos supor que a ditadura militar de Gomes da Costa e dos seus companheiros e depois a civil de Salazar serviram para preservar Portugal de um fim ou de uma situação que seria completamente desastrosa na altura, mas que levou o país, depois com Marcelo Caetano até à Revolução de 74, a encontrar o mundo já de maneira diferente, sem nenhuma potência pensar já em invadir-nos, e com as colónias a pensarem na sua própria independência.”.

${ }^{26}$ Cf., igualmente, AGOSTINHO DA SILVA, 1989, 170: "A I República, para mim, era uma coisa que não ia levar a sítio nenhum. Mais: estou convencido de uma coisa esquisita, segundo a qual, se não tivesse havido ditadura, provavelmente Portugal tinha acabado naquele momento, aí por 1925-26. Era uma confusão, ninguém se entendia, não parecia existir saída de espécie nenhuma. Por outro lado, havia ao lado uma Espanha, de Primo de Rivera e Afonso XIII, interessada em Portugal, mais uma Europa com os olhos postos nas Colónias e, de facto, podíamos ter entrado, nesse momento, num processo de dissolução. Então, o que é que foi a ditadura? Talvez tivesse sido a camada de gesso que se aplica na perna de um sujeito que quebrou um osso: é chato, cria pulgas, causa uma série de incómodos, mas aquilo lá se vai aguentando e, quando se tira o gesso, o mundo é outro.”. 
cabeça... fazer das colónias e de Portugal uma comunidade de língua portuguesa. Ideia que expus a Franco Nogueira quando vim a Portugal, em 1962, convidado pelo Governo português para discutir o estatuto do Centro de Estudos Portugueses em Brasília. O ministro Franco Nogueira, ministro dos Estrangeiros nessa altura, recebeu-me e pudemos conversar com toda a franqueza, perguntando-me ele se eu achava que a ideia de uma comunidade luso-brasileira seria bem recebida no Brasil, respondi-lhe que não. Exactamente por causa da atitude que Portugal estava a tomar com as colónias, com Angola naquela ocasião, o Brasil de nenhuma maneira ia aceitar isso, pois recordava-se muito bem que tinha sido colónia. A meu ver, Portugal tratou o Brasil muito bem quando foi colónia e se não tivessem sido os portugueses, o Brasil não se teria constituído. Mas o Brasil muitas vezes achava que os portugueses tinham tido defeitos na colonização - a meus olhos esses defeitos não existiram, embora houvesse muita coisa individual de tipo geralmente conotado com a colonização rapinante dos países. Mas não me parecia que naquela altura aceitassem uma coisa dessas. Mas havia algo que achava que aceitavam e que tomava a liberdade de expor a Franco Nogueira, que de resto tinha tido relações com um grande amigo meu, o poeta Casais Monteiro, e, portanto, eu podia falar com uma certa liberdade, por isso disse-lhe que o que me parecia que se devia fazer era uma comunidade luso-afro-brasileira com o ponto africano muito bem marcado. Quer dizer, se pudesse, eu poria o ponto central da comunidade, embora cada um dos países tivesse a sua liberdade, a sua autonomia, em África, talvez Luanda ou no interior de Angola, no planalto, de maneira que ali se congregassem Portugal e o Brasil para o desenvolvimento de África e para que se firmasse no Atlântico um triângulo de fala portuguesa Portugal, Angola, Brasil - que pudesse levar depois a outras relações ou ao oferecimento de relações de outra espécie aos outros países. Então Franco Nogueira disse-me que isso era completamente impossível, que Portugal não se podia dividir e que não havia nada a fazer nesse ponto. De maneira que eu continuo a pensar que, aquando da revolução em 1974, se poderia talvez ter tentado isso. No entanto, é muito possível que a situação tivesse avançado tanto, que a guerra tivesse castigado tanto, quer os africanos, quer os portugueses, que o que cada um queria era verse livre do outro. Portanto, não havia já nenhuma possibilidade de fazer senão o que se fez, uma descolonização decerto apressada, 
mas trazida pelas circunstâncias; parecia que não podia ser de outro modo e, no entanto, talvez a coisa pudesse ter tido outro caminho. Quanto a Timor, achava que podia ter sido incluído num quadro futuro de uma comunidade de língua portuguesa e desempenhar um papel importante.

Não, não me pareceu que a revolução de 1974 tal como estava a ser feita, conduzisse a alguma coisa em que valesse a pena colocar essas ideias. Pareceu-me que era um pronunciamento militar sem grande largueza política e que por outro lado se entrava em passo de pôr imediatamente Portugal a caminho de um regime parlamentarista que continuo a achar que não é o regime mais adequado a Portugal.” (AGOSTINHO DA SILVA, 1994, pp. 51-53)

Após o abrupto processo de descolonização - ou, talvez mais exactamente, de "abandono" 27 -, considerou Agostinho da Silva que, ainda assim, o grande projecto de futuro de Portugal passava por reatar os laços com os restantes países lusófonos, obviamente agora numa base de paridade. Esse projecto já deu lugar à CPLP: Comunidade dos Países de Língua Portuguesa, mas, como já aqui foi dito, esse projecto está ainda muito aquém do sonho agostiniano. Mais de vinte anos após a sua criação, é tempo, a nosso ver, de finalmente concretizarmos esse sonho, esse Horizonte...

Fiel a essa "Pátria de todos nós", a essa visão estratégica de Agostinho da Silva, tem sido o MIL: Movimento Internacional Lusófono, um movimento cultural e cívico recentemente criado mas que conta já com vários milhares de membros, de todo o espaço da lusofonia, e que tem defendido, de forma coerente e consequente, o reforço dos laços entre os países lusófonos ${ }^{28}$. Como já alguém escreveu, o que temos procurado fazer é "construir a CPLP por

\footnotetext{
${ }^{27}$ Como escreveu relativamente a Timor: "quando os portugueses abandonaram aquilo, e a verdade é que abandonaram mesmo aquilo" [AGOSTINHO DA SILVA, 1995, p. 74].

${ }^{28}$ Para mais informações: www.movimentolusofono.org. Ver igualmente: Convergência Lusófona: as posições do MIL: Movimento Internacional Lusófono, Lisboa, Zéfiro, 2016 ( $3^{\mathrm{a}}$ edição, revista e actualizada).
} 
baixo, ao nível da sociedade civil”. Desde logo, promovendo o sentido de cidadania lusófona, ainda tão incipiente na maior parte de nós. Ainda e sempre, promovendo o reforço dos laços entre os países lusófonos - no plano cultural, desde logo, mas também social, económico e político. Eis, a nosso ver, o novo Horizonte que se abre para Portugal, no reencontro com a sua História: a aposta na Convergência Lusófona, conforme defendemos no nosso já aqui referido livro A Via Lusófona: um novo horizonte para Portugal.

\section{VIII - Pensar a Lusofonia no século XXI}

No século XXI, para pensarmos a Lusofonia, temos que superar os paradigmas colonialistas e mesmo pós-colonialistas. Estes estão ainda reféns de um olhar enviesado por uma série de complexos históricos que há que transcender de vez, de modo a podermos realizar essa visão futurante do que pode ser a Lusofonia.

Transcender não significa escamotear. Indo directo ao assunto, é evidente que a Lusofonia se enraíza numa história que foi em parte colonial e, por isso, violenta. Não há colonialismos não violentos, por muito que possamos e devamos salvaguardar que nem todas as histórias coloniais tiveram o mesmo grau de violência. Eis, de resto, o que se pode aferir não apenas pelas análises históricas, mas comparando a relação que há, nos dias de hoje, entre os diversos povos colonizadores e colonizados. Assim haja honestidade para tanto.

Não será, porém, esse o caminho que iremos aqui seguir. Não pretendemos alicerçar a Lusofonia na relação que existe, nos dias de hoje, entre Portugal e os países que se tornaram independentes há mais de quarenta anos. Se assim fosse, estaríamos ainda a fazer de Portugal o centro da Lusofonia, estaríamos ainda a pensar à luz dos paradigmas colonialistas e mesmo pós-colonialistas.

O que pretendemos salientar é que, sem excepção, é do interesse de todos os países que se tornaram independentes há mais de quarenta anos a defesa e a difusão da Lusofonia. Eis, desde logo, o que se prova por nenhum desses países ter renegado a língua 
portuguesa como língua oficial. Se o fizeram, não foi decerto para agradar a Portugal. Foi, simplesmente, porque esse era o seu legítimo interesse, quer interno - para manter a unidade nacional de cada um dos países -, quer externo - fazendo da língua portuguesa a grande via de inserção na Comunidade Internacional.

Obviamente, cada caso tem as suas especificidades. Pela minha experiência, sou levado a afirmar que o povo que mais facilmente compreende a importância da Lusofonia é o povo timorense; porque ela foi a marca maior de uma autonomia linguística e cultural que potenciou a resistência à ocupação indonésia e a consequente afirmação de uma autonomia política que, como sabemos, só se veio a concretizar mais recentemente, já no século XXI. Mesmo após esse período, tem sido a Lusofonia o grande factor de resistência ao assédio anglo-saxónico, via, sobretudo, Austrália.

Contrapolarmente, o Brasil, pela sua escala, poderia ser o único país a ter a tentação de desprezar a mais-valia estratégica da Lusofonia. Nunca o fez, porém. Pelo contrário - apesar de alguns sinais contraditórios, a aposta na relação privilegiada com os restantes países e regiões de língua portuguesa parece ser cada vez maior. Quanto aos PALOPs: Países Africanos de Língua Oficial Portuguesa, essa também parece ser, cada vez mais, a aposta. Simplesmente, reiteramo-lo, porque é do interesse de cada um desses países este caminho de convergência. Por isso, é a Lusofonia um caminho de futuro. Por isso, é a Lusofonia um espaço naturalmente plural e polifónico, que abarca e abraça as especificidades linguísticas e culturais de cada um dos povos desta comunidade desde sempre aberta ao mundo.

\section{Referências}

AA.VV. Nova Águia: Revista de Cultura para o século XXI, Lisboa, Zéfiro, $1^{\circ}$ Semestre de 2008.

. Agostinho [da Silva], São Paulo, Green Forest do Brasil Editora, 2000. 
124 | Revista Opinião Filosófica, Porto Alegre, V. 09; Nº. 01, 2018

DA SILVA, George Agostinho. A Última Conversa, Lisboa, Notícias, 1995.

. Conversas com Agostinho da Silva, entrevista de Victor Mendanha, Lisboa, Pergaminho, 1998.

. Dispersos, Lisboa, ICALP, 1989 ( ${ }^{\text {a }}$, revista e aumentada).

. Ensaios sobre Cultura e Literatura Portuguesa e Brasileira, Lisboa, Âncora, 2000

. O Império acabou. E agora?, entrevista de Antónia de Sousa, Lisboa, Notícias, 2001.

. Textos e Ensaios Filosóficos, Lisboa, Âncora, 1999.

. Vida Conversável (segunda parte, inédita), 2016.

. Vida Conversável, Lisboa, Assírio \& Alvim, 1994.

EPIFÂNIO, Renato. A Via lusófona: um novo horizonte para Portugal, Lisboa, Zéfiro, 2010.

. Perspectivas sobre Agostinho da Silva, Lisboa, Zéfiro, 2008.

MARINHO, José. Estudos sobre o pensamento português contemporâneo, Lisboa, Biblioteca Nacional, 1981.

. Filosofia portuguesa e universalidade da filosofia e outros textos, “Obras de José Marinho”, vol. VIII, Lisboa, Imprensa Nacional - Casa da Moeda, 2007.

. Filosofia: ensino ou iniciação?, Lisboa, Fundação Calouste Gulbenkian, Centro de Investigação Pedagógica, 1972.

. O Pensamento Filosófico de Leonardo Coimbra e outros textos, "Obras de José Marinho”, vol. IV, Lisboa, Imprensa Nacional - Casa da Moeda, 2001. 